\title{
PETROLEUM ETHER EXTRACT OF CISSUS QUADRANGULARIS (LINN) STIMULATES THE GROWTH OF FETAL BONE DURING INTRA UTERINE DEVELOPMENTAL PERIOD: A MORPHOMETRIC ANALYSIS
}

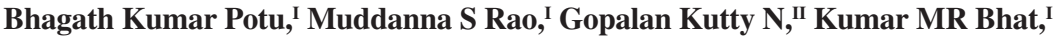 \\ Mallikarjuna Rao Chamallamudi, ${ }^{\text {II }}$ Soubhagya Ranjan Nayak ${ }^{\text {III }}$
}

doi: $10.1590 / \mathbf{S 1 8 0 7 - 5 9 3 2 2 0 0 8 0 0 0 6 0 0 0 1 8}$

Potu BK, Rao MS, Kutty NG, Bhat KMR, Chamallamudi MR, Nayak SR. Petroleum ether extract of Cissus quadrangularis (LINN) stimulates the growth of fetal bone during the intra-uterine developmental period: a morphometric analysis. Clinics. 2008;63:815-20.

OBJECTIVE: The aim of the present study was to analyze the effect Cissus quadrangularis plant petroleum ether extract on the development of long bones during the intra-uterine developmental stage in rats.

METHODS: Pregnant rats $(\mathrm{n}=12)$ were randomly assigned into either a control group $(\mathrm{n}=6)$ or a Cissus quadrangularis treatment $(\mathrm{n}=6)$ group. Pregnant rats in the Cissus quadrangularis group were treated with Cissus quadrangularis petroleum ether extract at a dose of $500 \mathrm{mg} / \mathrm{kg}$ body weight from gestation day 9 until delivery. The animals in the control group received an equal volume of saline. Newborn pups were collected from both groups for alizarin red S - alcian blue staining to differentiate ossified and unossified cartilage. The ossified cartilage (bone) was morphometrically analyzed using Scion image software.

RESULTS: Morphometric analysis revealed that the percentage of the total length of ossified cartilage (bone) in pups born to treated dams was significantly higher $(\mathrm{P}<0.001-0.0001)$ than that of the control group.

CONCLUSION: The results of the present study suggest that maternal administration of Cissus quadrangularis petroleum ether extract during pregnancy can stimulate the development of fetal bone growth during the intra-uterine developmental period.

KEYWORDS: Estrogens; Phytoestrogens; Ossification; Alizarin red-Alcian blue.

\section{INTRODUCTION}

There is increasing evidence that the intra-uterine environment influences the risk of developing chronic diseases such as cardiovascular disease, diabetes, and osteoporosis later in life. ${ }^{1}$ This is thought to occur through fetal programming, which refers to the ability of changes in

\footnotetext{
I Department of Anatomy, Kasturba Medical College, Manipal University Manipal, Karnataka, India.

"Department of Pharmacology, Manipal College of Pharmaceutical Sciences - Manipal, Karnataka, India.

III Department of Anatomy, Kasturba Medical College, Manipal University - Mangalore, Karnataka, India.

Email:muddannas@yahoo.com

Tel.: 919986088926

Received for publication on July 18, 2008

Accepted for publication on September 1, 2008
}

environmental factors (e.g., nutrition, stress, and exposure to toxins) at critical periods during development to permanently alter the structure, physiology, or metabolism of the body. ${ }^{1}$ Exposure to ethanol in utero has a number of effects on the developing skeleton, while these effects do not appear to normalize after birth. ${ }^{2}$ Cissus quadrangularis (CQ) is a weed plant that is used commonly in India and Sri Lanka to hasten the fracture healing process..$^{3-5}$ Leaf, stem, and root extracts from this plant are used in the management of various ailments. ${ }^{6-14}$ Phytochemical analysis of Cissus quadrangularis revealed a high content of ascorbic acid, carotene, phytosterol substances, and calcium,,$^{15}$ and there are reports of the presence of $\beta$-sitosterol, $\delta$-amyrin, and $\delta$-amyrone. ${ }^{16}$ All of these components have potentially different metabolic and physiological effects. ${ }^{17-19}$ Phytoestrogens, which are widely present in different plants in our environment, seem to have 
actions similar to estrogen on bone cells in vitro. ${ }^{20,21}$ Estrogen receptors have been detected in bone cells, both in osteoblasts and osteoclasts, ${ }^{22-24}$ suggesting the direct action of estrogens on these bone cells. Several studies have shown that estrogens can modulate bone cell physiology in vitro by a direct estrogen receptor-mediated mechanism. ${ }^{25-26}$ This evidence implicates a direct effect of estrogen on the skeleton and alternatively on bone tissue turnover. Although several excellent reviews have documented the beneficial effects of phytoestrogens on humans and laboratory animals, ${ }^{20,21}$ none have reported on the role of phytoestrogens on fetal rat bone ossification.

In our previous studies, we have demonstrated the effect of an ethanol extract of CQ on the ossification of fetal long bones and the thicknesses of cortical and trabecular bones of neonatal pups treated during days 9 through 21 of gestation. ${ }^{18,19}$ In our quest to identify and isolate the active principles of the CQ extract, we have more effectively extracted specific chemical compounds from the plant using different organic solvents, and have tested these extracts for their osteostimulant role in vitro. We have observed that CQ petroleum ether extract has a pronounced effect on osteoblasts (unpublished data); however, it is still unknown whether this CQ petroleum ether extract similarly affects the development of bone in utero. Therefore, it is reasonable to study the role of this extract, which is believed to extract the phytogenic steroids in the plant, on the development of fetal bones. Considering the paucity of available data concerning the effect of medicinal plants on the ossification of fetal bone, we aimed to systematically evaluate the in vivo effect of CQ petroleum ether extract on the skeletons of neonatal pups treated during the gestation period.

\section{MATERIALS AND METHODS}

\section{Plant material and extraction}

The stem of Cissus quadrangularis was collected from the Nalgonda District of Andhra Pradesh in India, identified, and authenticated by a botanist. A voucher specimen was deposited in the Pharmacology Department of Manipal University. The fleshy stems $(2.5 \mathrm{~kg})$ were washed, cut into small pieces, air-dried, and crushed into powder. The stem powder was exhaustively extracted with $95 \%$ ethanol using a Soxhlet apparatus, and a extract yield of $225 \mathrm{~g}$ was obtained. The total ethanol extract was concentrated in a vacuum, dissolved in water, and then partitioned with petroleum ether to obtain a petroleum ether extract at a yield of $18.2 \mathrm{~g}$.

\section{Chemicals}

Alizarin red S, alcian blue 8GX, and paraformaldehyde were purchased from Sigma Chemicals (USA). Potassium hydroxide and glycerol were obtained from Merck (India).

\section{Animals}

Twelve 3-month-old female Wistar rats weighing approximately $225 \mathrm{~g}$ were housed in the Central Animal Research Facility of Manipal University. The rats were housed in sanitized polypropylene cages containing sterile paddy husk as bedding. The animals were maintained under controlled conditions at a temperature of $23 \pm 2{ }^{\circ} \mathrm{C}$, humidity of $50 \pm 5 \%$, and a 12 -h light- dark cycle. All animals were allowed free access to water and fed on a commercial diet. All of the conducted studies were approved by the Institutional Animal Ethical Committee (No.IAEC/ KMC/06/2006-2007), Kasturba Medical College, Manipal, according to the prescribed guidelines of the Committee for the Purpose of Control and Supervision of Experiments on Animals (CPCSEA), according to prescribed guidelines of the Government of India.

In order to impregnate the test rats and obtain a known gestational day, female rats in an estrous cycle were mated with young healthy male rats and subjected to a vaginal smear test after 12 hours. Detection of sperm in the vaginal smear was considered day 0 of pregnancy.

\section{Acute toxicity study}

Acute toxicity was measured on fasting rats. Animals were divided into groups of 10 each and orally given 500, $1000,1500,2500,3000,3500,4000,4500$, and $5000 \mathrm{mg} / \mathrm{kg}$ body weight of CQ. The rats were continuously observed for 2 hours, checked regularly at one hour interval up to 6 hours, and daily thereafter for 30 days. Mortality, if any, was recorded. ${ }^{27}$

\section{Experimental protocol}

Pregnant rats were divided into control and CQ-treated groups ( $\mathrm{n}=6$ in each group). Pregnant rats in the treated group were treated with CQ petroleum ether extract of 500 $\mathrm{mg} / \mathrm{kg} /$ day from gestation day 9 until delivery. The control group received an equal volume of saline.

At the end of the experiment, i.e., the day of birth, all the pups born to control and treated mothers were collected.

Under anesthesia, the skin, viscera, and adipose tissue were carefully removed from the newborn pups. All the eviscerated pups were fixed in $95 \%$ ethanol for 5 days and then processed for alizarin red $\mathrm{S}$ - alcian blue double staining to view the entire skeleton. ${ }^{28}$ 


\section{Measurement of ossified skeleton (bone) and total skel- eton length}

The alizarin red-alcian blue-stained limbs were photographed with scales to measure the ossified skeleton length and the total lengths of the forelimb and hindlimb bones. The length of the ossified skeleton (bone) was measured using Scion image software for Windows (NIH software). The software was calibrated and the length was measured as a grey scale image (BMP) of the original JPEG image. The lengths of the humerus, radius, ulna, femur, tibia, and fibula were measured ( $\mathrm{n}=6$ limbs in each group), and the percentages of the total lengths of the mineralized skeletons in the control and treated groups were calculated.

Statistical analysis:

Data are expressed as mean \pm SEM (standard errors of mean). Data were analyzed by Student's t-test. Probability $(\mathrm{P})$ values less than 0.05 were considered significant.

\section{RESULTS}

The oral administration of Cissus quadrangularis plant petroleum ether extract did not cause mortality or any signs of clinical abnormality in the treated pregnant rats.

The Scion image data revealed a significant difference in the extent of ossification of the bones of the treated group compared to the control group.

\section{The effect of CQ petroleum ether extract on the ossifi- cation of the humerus}

The scion image data concerning the length of ossified skeleton revealed a significant difference in the extent of ossification of the humerus in treated compared to control pups. The mean length of the ossified humerus in the control pups was $3.97 \pm 0.06 \mathrm{~mm}(\mathrm{n}=6 ; 64.97 \pm 1.09 \%$ of total length of the humerus), while the mean length of the ossified humerus in pups born to CQ-treated mothers was $4.36 \pm$ $0.04 \mathrm{~mm}$ ( $\mathrm{n}=6 ; 73.84 \pm 0.89 \%$ of total length of the humerus $(\mathrm{P}<0.0001$, Student's t-test; Figures 1 and 2).

\section{Effect of the CQ extract on the ossification of the radius and ulna}

The lengths of the ossified radius and ulna were found to be $3.58 \pm 0.02 \mathrm{~mm}(\mathrm{n}=6 ; 66.73 \pm 1.09 \%$ of total length $)$ and $4.42 \pm 0.03 \mathrm{~mm}(\mathrm{n}=6 ; 74.16 \pm 0.61 \%$ of total length $)$, respectively, in the control pups. The lengths of the ossified radius and ulna of pups born to treated mothers were found to be significantly increased compared to the control pups (Radius: $3.64 \pm 0.04 \mathrm{~mm}, \mathrm{n}=6 ; 72.49 \pm 0.79 \%$ of total

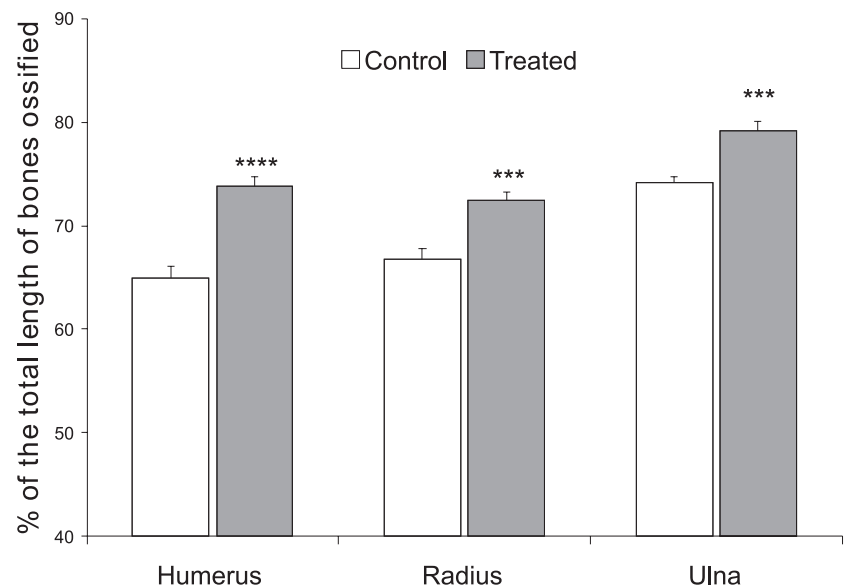

Figure 1 - Percentages of total lengths of humerus, radius, and ulna ossified in pups born to control and treated (petroleum ether extract of CQ, $500 \mathrm{mg}$ / $\mathrm{kg} /$ day) mothers. Note that there are significant increases in the lengths of the ossified humerus, $(* * * * \mathrm{P}<0.0001$, Student's t-test), radius, and ulna (*** $\mathrm{P}<0.001$ Student's t-test) in pups born to CQ-treated mothers

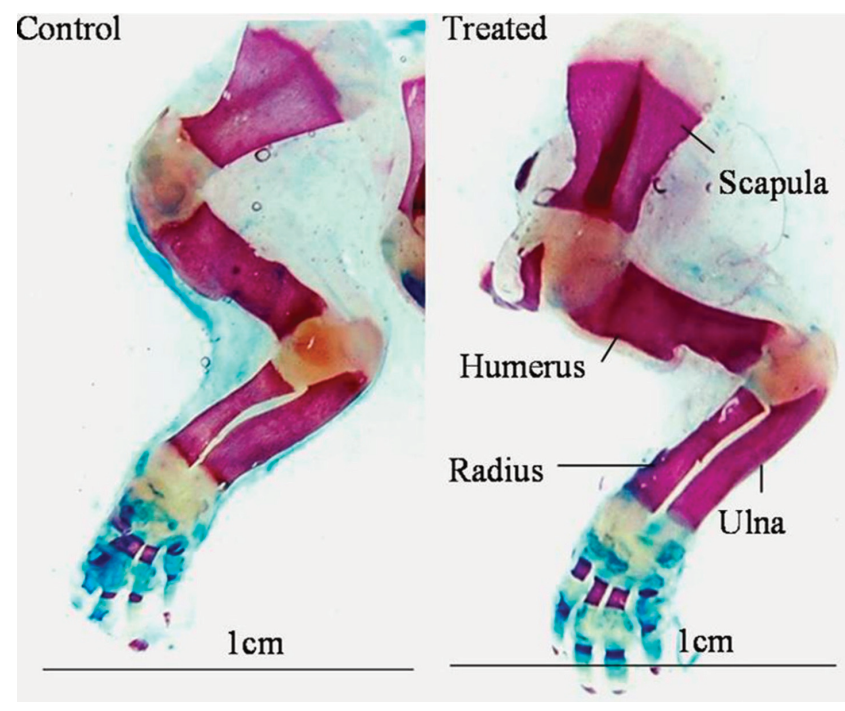

Figure 2 - Photograph of Alizarin red S and alcian blue-stained forelimbs showing the ossified and unossified portions of bones in pups born to control or CQ petroleum ether extract-treated mothers. Note the increased lengths of the humerus, radius, and ulna in the treated group. Scale bar $=1 \mathrm{~cm}$ in both photographs

length $(\mathrm{P}<0.001)$; Ulna: $4.68 \pm 0.05 \mathrm{~mm}, \mathrm{n}=6 ; 79.14 \pm$ $0.97 \%$ of total length $(\mathrm{P}<0.001$, Student's t-test; Figures 1 and 2).

\section{The effect of the CQ extract on the ossification of the femur}

The length of the ossified femur was $3.06 \pm 0.02 \mathrm{~mm}$ ( $\mathrm{n}=6 ; 52.52 \pm 0.35 \%$ of total length) in the control pups and $3.66 \pm 0.04 \mathrm{~mm}$ in pups born to CQ-treated mothers $(\mathrm{n}=6$; 


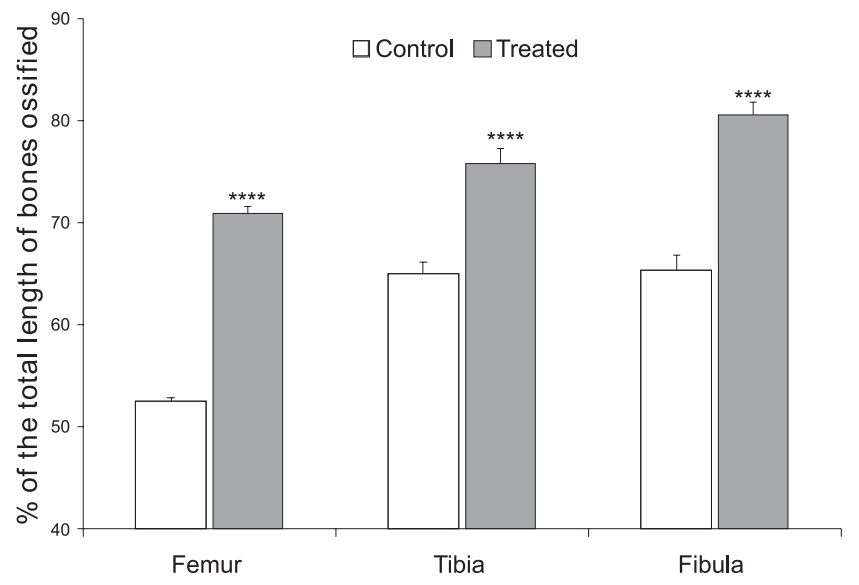

Figure 3 - Percentages of total lengths of femur, tibia, and fibula ossified in pups born to control or CQ petroleum ether extract-treated mothers. Note there is a significant increase in the lengths of the ossified femur, tibia, and fibula (**** $\mathrm{P}<0.0001$, Student's t-test)

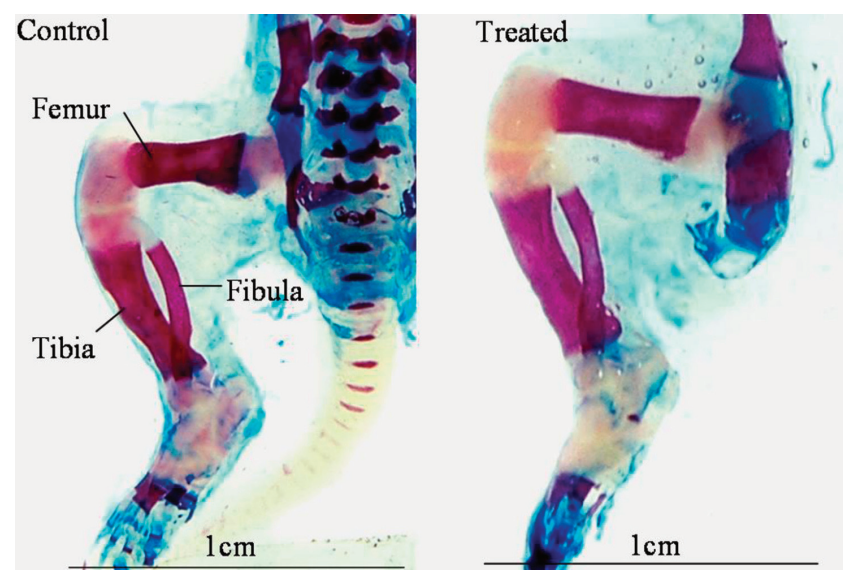

Figure 4 - Photograph of Alizarin red S and alcian blue-stained pup hindlimbs showing the ossified and unossified portions of bones in pups born to control or CQ petroleum ether extract-treated mothers. Note the increased lengths of the femur, tibia, and fibula in the treated group. Scale bar $=1 \mathrm{~cm}$ in both photographs

$70.85 \pm 0.70 \%$ of total length, $\mathrm{P}<0.0001$ Student's t-test, Figures 3 and 4).

\section{The effect of the extract on the ossification of the tibia and fibula}

The lengths of the ossified tibia and fibula were $3.77 \pm$ $0.14 \mathrm{~mm}(\mathrm{n}=6 ; 64.97 \pm 1.17 \%$ of total length $)$ and $3.41 \pm 0.04$ $\mathrm{mm}(\mathrm{n}=6 ; 65.34 \pm 1.41 \%$ of total length), respectively, in the control group. The lengths of the ossified tibia and fibula of in pups born to the treated mothers were found to be significantly increased compared to control pups (Tibia: $4.17 \pm 0.07 \mathrm{~mm}$, $\mathrm{n}=6 ; 75.77 \pm 1.52 \%$ of total length $(\mathrm{P}<0.0001$, Student's t-test); Fibula: $4.12 \pm 0.05 \mathrm{~mm}, \mathrm{n}=6 ; 80.55 \pm 1.21 \%$ of total length ( $\mathrm{P}<0.0001$, Student's t- test; Figures 3 and 4).

\section{DISCUSSION}

This study evaluates the effect of CQ petroleum ether extract on the ossification of the fetal skeleton. Pups born to mothers treated with $500 \mathrm{mg} / \mathrm{kg}$ of CQ from gestation day 9 until delivery exhibited a significant increase in the lengths of the ossified parts of the skeleton in both forelimbs and hindlimbs. This study is an extension of our previous investigations on the effect of CQ extract on the development of the fetal skeleton in rats. In that study, we reported that the treatment of pregnant rats with a CQ ethanolic extract of $750 \mathrm{mg} / \mathrm{kg} / \mathrm{day}$ enhanced the ossification of the fetal skeleton. ${ }^{18}$ The present study demonstrates, for the first time, that maternal treatment with petroleum ether extracts during gestation can dramatically influence the skeleton of the fetus.

In the present study, CQ was used at a dose of $500 \mathrm{mg} /$ $\mathrm{kg}$ body weight based on our acute toxicity studies. This dose appears to be safe, as treated animals did not show any adverse effects; however, a dose-response study is essential to determining the minimum effective dose that shows a maximum effect.

The increased mineralization (ossification) observed in the present study could be attributed to the phytogenic steroid compounds isolated from this plant, which may have altered the maternal estrogen levels or reached the growing fetus through the placenta. ${ }^{15}$ Singh et. al. ${ }^{12}$ have reported the presence of several phytosteroids in the extract of CQ. It has been reported that such phytosteroids can pass through the placental barrier. ${ }^{30,31}$ This was observed in the study by Magliaccio et al. ${ }^{31}$ wherein they altered the maternal estrogen levels by providing external steroidal hormones, and demonstrated alterations in the skeletons of neonatal pups. The bone growth observed in pups born to treated mothers in the present study may be due to proliferation and differentiation of chondrocytes. This may be regulated by phytogenic steroids probably present in the CQ petroleum ether extract, which may act as an analog of estrogen. It has been reported that estrogen stimulates proliferation and differentiation of the chondrocytes and thereby increases bone length. ${ }^{32}$

Animal experiments have demonstrated that hormones affect development during sensitive periods of early life and permanently program the structure and physiology of the bone tissues. ${ }^{33}$ It is well known that changes in estrogen levels can dramatically modify bone tissue turnover in both postmenopausal women ${ }^{34}$ and ovarectomized animals. ${ }^{35} \mathrm{In}$ addition, long term exposure of adult animals to estradiol or diethylstilbestrol induces hyperplasia of bone tissue. ${ }^{22}$

These data strongly suggest that bone tissue directly responds to estrogen-like target tissues. 
Further, transient neonatal exposure of female mice to estrogen has been shown to increase the bone mass in the animals during adulthood. ${ }^{26}$ Thus, these data strongly suggest that alterations of estrogen levels before puberty, especially in early phases of development, can dramatically influence skeletal maturation, including final peak bone density. Perturbation in the maternal estrogen level during pregnancy has been shown to alter the developing skeleton. ${ }^{31}$ Evidence indicates that osteoporosis can be triggered during the intrauterine growth period and can result in a defective skeleton for newborn offspring. ${ }^{33}$ In these cases, treatment with a petroleum ether extract may be useful in reversing/ preventing the osteoporotic fractures and improving the bone mineral density.
In conclusion, the results of the present study provide evidence that CQ petroleum ether extract is a promising agent for treating intrauterine growth defects in the skeletal system. Further studies on the isolation and characterization of the active chemical constituents of CQ petroleum ether extract that are responsible for bone anabolic activity are warranted; however, further basic studies and clinical trials will be needed to substantiate the efficacy of Cissus quadrangularis.

\section{ACKNOWLEDGEMENTS}

We thank Dr. Narga Nair, Professor and Head, Department of Anatomy, Kasturba Medical College, Manipal University, Manipal, for her support of this study.

\section{REFERENCES}

1. Barker DJP. Mothers, babies and health in later life. 2nd ed. Churchill Livingstone: Edinburgh; 1998

2. Day NL, Leech SL, Richardson GA, Cornelius MD, Robles N, Larkby C. Prenatal alcohol exposure predicts continued deficits in offspring size at 14 years of age. Alcohol Clin Exp Res. 2002;26:1584-91.

3. Deka DK, Lahon LC, Saikia J, Mukit A. Effect of Cissus quadrangularis in accelerating healing process of experimentally fractured radius-ulna of dog, a preliminary study. Indian J of Pharmacol. 1994;26:44-5.

4. Udupa KN, Prasad GC. Further studies on the effect of Cissus quadrangularis in accelerating fracture healing. Indian J Med Res. 1964;52:26-35.

5. Udupa KN, Prasad GC. Cissus quadrangularis in healing of fractures. A clinical study. J Indian Med Assoc. 1962; 38:590-593.

6. Chidambara Murthy KN, Vanitha A, Mahadeva Swamy M, Ravishankar GA. Antioxidant and antimicrobial activity of Cissus quadrangularis. L J Med Food. 2003; 6:99-105.

7. Singh SP, Mishra N, Dixit KS, Singh N, Kohli RP. An experimental study of analgesic activity of Cissus quadrangularis. Indian J of Pharmacol. 1984;79:162-63.

8. Oliver-Bever B. Medicinal plants in tropical West Africa. II. Plants acting on the nervous system. J Ethnopharmacol. 1983;7:1-93.

9. Jainu M, Devi CS. Gastroprotective action of Cissus quadrangularis extract against NSAID induced gastric ulcer: role of proinflammatory cytokines and oxidative damage. Chem Biol Interact. 2006;161:26270.

10. Jainu M, Mohan KV, Devi CS. Protective effect of Cissus quadrangularis on neutrophil mediated tissue injury induced by aspirin in rats. J Ethnopharmacol. 2006; 104:302-5.
11. Oben JE, Ngondi JL, Momo CN, Agbor GA, Sobgui CS. The use of a Cissus quadrangularis/Irvingia gabonensis combination in the management of weight loss: a double-blind placebo-controlled study. Lipids Health Dis. 2008;7:12.

12. Singh G, Rawat P, Maurya R. Constituents of Cissus quadrangularis. Nat Prod Res. 2007;21:522-8.

13. Panthong A, Supraditaporn W, Kanjanapothi D, Taesotikul T, Reutrakul V. Analgesic, anti-inflammatory and venotonic effects of Cissus quadrangularis Linn. J Ethnopharmacol. 2007;110:264-70.

14. Jain A, Dixit J, Prakash D. Modulatory effects of Cissus quadrangularis on periodontal regeneration by bovine-derived hydroxyapatite in intrabony defects: exploratory clinical trial. J Int Acad Periodontol. 2008;10:59-65.

15. Sen SP. Study of the active constituents (ketosteroids) of Cissus quadrangularis. Indian J of Pharmacol. 1964;4:247.

16. Mehta M, Kaur N, Bhutani KK. Determination of marker constituents from Cissus quadrangularis Linn. and their quantitation by HPTLC and HPLC. Phytochem Anal. 2001;12:91-5.

17. Shirwaikar A, Khan S, Malini S. Antiosteoporotic effect of ethanol extract of Cissus quadrangularis Linn. on ovariectomized rat. J Ethnopharmacol. 2003; 89:245-50.

18. Potu BK, Rao MS, Swamy NVB, Kutty GN. Cissus quadrangularis plant extract enhances the ossification of fetal bones. Pharmacologyonline. 2007; $1: 63-70$

19. Rao MS, Potu BK, Swamy NVB, Kutty GN. Cissus quadrangularis plant extractenhances the development of cortical bone and trabeculae in the fetal femur. Pharmacologyonline. 2007;3:190-202. 
20. Adlercreutz H, Mazur W: Phytoestrogens and Western diseases. Ann. Med. 1997;29:95-120.

21. Adlercreutz H: Phytooestrogens and cancer. Lancet Oncol. 2002;3:36473.

22. Greenman DI, Delongchamp RR. Interactive response to DES in $\mathrm{CH} 3$ mice. Food Chem Toxicol. 1986;24:931-34.

23. Eriksen EF, Colvard DS, Berg NJ, Graham ML, Mann KG, Spelberg $\mathrm{TC}$, et al. Evidence of estrogen receptor in normal human osteoblast like cells. Science. 1988;241:84-6.

24. Gray TK, Flynn TC, Gray KM, Nabell LM. 17ßestrodiol acts directly on the clonal osteoblastic cell line UMR-106. PNAS. 1987;84:6267-71

25. Ernst M Parker MG, Rodan GA. Functional estrogen receptor in osteoblastic cellsdemonstrated by transfection with a receptor gene containing an estrogen responseelement. Mol Endocrinol. 1991;5:159706.

26. Migliaccio S, Davis VL, Gibson MK, Gray KT, Korach KS. Estrogens modulate theresponsiveness of osteoblast like cells (ROS 17/2. 8) stably transfected with estrogen receptor. Endocrinology. 1992;130:261724.

27. Ghosh. MN. Fundamentals of Experimental Pharmacology, 2nd Ed, Calcutta, India: Scientific Book Agency. 1984; pp. 153-57.

28. Minoru I. Differential staining of cartilage and bone in fetal mouse skeleton by alcian blue and alizarin red s. Cong. Anom. 1976;16:17173.
29. Todaka E, Sakurai K, Fukata H, Miyagawa H, Uzuki M, Omori M, et al. Fetal exposure to phytoestrogens - the difference in phytoestrogens status between mother and fetus. Environ. Res. 2005;99:195-203.

30. Mustafa AM, Malintan NT, Seelan S, Zhan Z, Mohamed Z, Hassan $\mathrm{J}$, et. al. Phytoestrogens levels determination in the cord blood from Malaysia rural and urban populations. Toxicol and Appl Pharmacol. 2007;222:25-32.

31. Migliaccio S, Newbold RR, Bullock BC, Jefferson WJ, Sutton FG JR, Mclachlan JA, et. al. Alterations of maternal estrogen levels during gestation affect the skeleton of female offspring. Endocrinology. 1996;137:2118-25.

32. Chagin AS, Chrysis D, Takigawa M, Ritzen EM, Savendahl L. Locally produced estrogen promotes fetal rat metatarsal bone growth; an effect mediated through increased chondrocytes proliferation and decreased apoptosis. Journal of Endocrinology. 2006; 188: 193-203.

33. Cooper C, Javaid MK, Taylor P, Walker Bone K, Dennison E, Arden N. Fetal origin of osteoporotic fractures. Calcif Tissue Int. 2002;70:39194.

34. Lindsay R, Hart DM, Aikken JM, McDonald EB, Anderson JB, Clark AC. Long-term prevention of postmenopausal osteoporosis by estrogen: evidence of an increased bone mass after delayed onset of estrogen treatment. Lancet. 1976;1:1038-40.

35. Wronsky TJ, Cintron M, Doherty AL, Dann LM. Estrogen treatment prevents osteopenia and depresses bone turnover in ovariectomized rats. Endocrinology. 1988; 123:681-86. 